\title{
The Evaluation of Governmental Research Institues of Turkey and Certain EU Member States Regarding to Marine Fisheries in Terms of Their Substructure and Researcher Characteristics
}

\author{
Senel Birceyudum Eman Gokseven \\ Republic of Turkey Ministry of Agriculture and Forestry, Directorate General for European Union and \\ Foreign Relations, Ankara, Turkey \\ E-mail: beman2023@gmail.com \\ Ilknur Meric Turgut (Corresponding author) \\ Department of Fisheries and Aquaculture Engineering, Faculty of Agriculture \\ Ankara University, 06110, Ankara, Turkey \\ E-mail: meric@agri.ankara.edu.tr
}

This research was compiled from the MSc. Thesis of Şenel Birceyudum Eman Gökseven under the supervision of Assoc. Prof. Dr. Illknur Meriç Turgut.

\begin{abstract}
The $30 \%$ of the world's fisheries production has been supplied by aquaculture and it has been expanded more than $10 \%$ annually as stated by FAO. However, it is in a state of conflict with other facilities as waning the diversion of species, the revealing of invasive kinds and the competition of third countries via faced with challenges as environmental impacts. The European Union (EU), as one of the biggest importer in aquaculture sector, is focusing on research and innovation so as to increase the potential of natural resources and to overcome the issues as mentioned above. Within the scope of this research, it has been thought that the feasibilities of the research substructure are equal among Turkey and EU countries and they have been performing facilities in similar numbers and quality. In the mean time, as 7 . Frame programme in the 2007-2013 period, Turkey has an unignorable shareholder potential and will be an important actor in terms of partnership in Horizon 2020 and other EU science programmes.
\end{abstract}

Keywords: Turkey, European Union, Marine Fisheries, Research Institues, Researcher Characteristics

DOI: $10.7176 / J S T R / 5-2-31$

\section{Türkiye ve Avrupa Birliği Üyesi Bazı Ülkelerde Deniz Balıkçılığı Alanında Faaliyet Gösteren Kamu Araştırma Enstitülerinin Altyapı ve Araştırıcı Özellikleri Açısından Değerlendirilmesi}

Özet

FAO tarafından dünya balıkçılık üretiminin yaklaşık \%30'unu su ürünleri yetiştiriciliğinin karşıladığg ve yılda \%10'dan fazla büyüdüğü belirtilmektedir. Ancak, su ürünleri sektörü, tür çeşitliliğinin azalması, 
istilacı türlerin ortaya çıkması ve üçüncü ülkelerle rekabet gibi diğer faaliyetler ile çatışma içinde ya da negatif çevresel etkiler gibi zorluklarla karşı karşıyadır. Avrupa Birliği (AB), dünyadaki en büyük su ürünleri ithalatçılarından biri olarak, su ürünleri alanındaki bu zorlukların üstesinden gelmek ve doğal kaynakların potansiyelini artırmak amacıyla araştırma ve yeniliğe odaklanmıştır. Çalışma kapsamında ele alınan AB ülkeleri ile Türkiye'nin araştırma alt yapı olanaklarının eşdeğer olduğu ve benzer sayı ile nitelikte araştırma faaliyetleri yürüttüğü, aynı zamanda 2007-2013 döneminde 7. Çerçeve programında olduğu gibi Horizon 2020 ve diğer AB bilim programları ve ortaklıkları açısından önemli bir partner ve paydaş potansiyeline sahip olduğu da düşünülmektedir.

Anahtar Kelimeler: Türkiye, Avrupa Birliği, Deniz Balıkçılığı, Araştırma Enstitüleri, Araştırıcı özellikleri

\section{Giris}

Dünyada pek çok gelişmiş ülke, su ürünleri ile ilgili olarak balık stokları, tür biyolojisi, ekolojisi ve genetiği, avlanma teknolojisi, işleme teknolojisi ve yetiştiriciliğine ilişkin araştırma faaliyetlerinin yanı sıra su ürünleri kaynakları, çevresel ortamları ile su ve canlı kaynakların yönetimine ilişkin çalışmalar yürütmektedir. Özellikle su ürünleri stokları ve bu stokların verimliliğini, büyüklüğünü etkileyen biyolojik ve ekolojik etkenler ile su ve canlı kaynaklarda kirlilik ve bu kaynakların kirlilikten korunması konularında izlemeye dayalı çalışmalar periyodik olarak yapılmaktadır (DPT, 2003). İzleme ve araştırmaya yönelik bu çalışmalar, kamu kurumlarına ait araştırma enstitüleri, yetiştiriciler ve üniversite işbirliği ve desteği ile gerçekleştirilmektedir. Avrupa Birliği (AB), en büyük su ürünleri ithalatçısı olarak yürüttüğü araştırma ve bilim programları ile su ürünleri kaynaklarının izlenmesi ve yönetimine ilişkin lider bir pozisyona sahiptir.

AB'ye üye ülkelerin, 1957'de Avrupa balıkçılık sektörü için Birliğe ortak kurallar koyma yetkisi tanımasıyla başlayan süreçte, balık stoklarının korunması ve işletilmesi amacıyla, 1983 yılında AB çapında bir Ortak Balıkçılık Politikası (OBP) üzerinde anlaşmaya varılmıştır (Kilit, 2012). OBP, balık stoklarının korunması esasına dayanan ve Avrupa balıkçılık filolarının belirli kurallar dahilinde yönetilmesine olanak veren bir politika olmuştur (Anonymous, 2014b; Eman Gökseven ve ark, 2018). Ortak bir kaynağı yönetmek ve dinamik bir balıkçılık sektörü geliştirmek için tasarlanan bu politika, tüm Avrupa balıkçı filolarına, AB sularına ve balıkçılık alanlarına eşit erişim imkanı sunmakta ve balıkçıların adil bir şekilde rekabet etmesine izin vermektedir. OBP'nin; balıkçılık yönetimi, uluslararası politika, piyasa ve ticaret politikası ile yapısal politika olmak üzere dört ana unsuru bulunmaktadır. OBP ayrıca yetiştiricilik ve paydaş katılımı üzerine de kurallara sahiptir (Anonymous, 2016a; Eman Gökseven ve ark, 2018).

OBP'nin dört bileşeninden birini oluşturan Balıkçılık Yönetimi bileşeni, su ürünlerinin ve deniz ekosisteminin sürdürülebilir kullanımını sağlamak amacıyla bilimsel çalışmalara önem veren bir politika belirlemektedir. OBP'nin 1380/2013 sayılı Temel Tüzük'ünde de bilimsel verilerin tutulmasındaki önem bu kapsamda vurgulanmıştır.

Sucul kaynaklara ait güvenilir ve güncel bilgilerin edinilmesi, böylelikle üye devletlerin balık stokları konusunda doğru yönetsel kararlar alabilmesi ve bilimsel zeminin sağlanabilmesi amacıyla OBP'de birtakım yenilikler yapılması öngörülmüştür. Balık stokları hakkında bilimsel verilerin elde edilmesinden üye devletler sorumlu olup söz konusu eylemin koordine edilmesi amaciyla ulusal araştırma programlarının oluşturulması öngörülmüştür. Ulusal araştırma programları çerçevesinde, üye devletlerden ulusal düzeyde bilimsel veri toplama ve yenilik programları oluşturmaları beklenmektedir. Ayrıca, üye devletler, Birliğin araştırma ve yenilik çerçeve programları ışığında, veri toplama, araştırma ve yenilik aktiviteleri için diğer üye devletler ile olan koordinasyonu sağlamalı ve yeterli miktarda kaynağı bilimsel danışmanlık süreci için ayırmalıdır (Anonim, 2012).

AB Araştırma ve Yenilik Genel Müdürlüğü, su ürünleri avcılık ve yetiştiricilik alanında başlıca fon sağlayıcı olarak rol oynamaktadır. Fon, Araştırma Çerçeve Programları kapsamında yürütülen AB seviyesinde ileri araştırma projeleri aracılığıyla sağlanmaktadır. İlki 1984 yılında başlayan ve dünyanın en büyük bütçeli sivil araştırma programı olan AB Çerçeve Programları (AB ÇP) Avrupa'nın bilim ve teknoloji politika ve uygulamalarının birbirine yakınlaştırılması ve uyumlaştırılması amacıyla oluşturulan Topluluk Programları'ndan birisidir (TÜBİTAK, 2011). Bu programların amacı, Avrupa'nın bilim ve teknoloji alt yapısını güçlendirmek, ekonomik ve sosyal uyumu desteklemek, küresel düzeyde endüstriyel rekabeti sağlamak, üniversite-sanayi işbirliğini teşvik etmek ve AB üye ülkeleri arasında işbirliğini teşvik etmektir (Pınar ve Uzunoğlu, 2009). Bu programlar, balıkçılık ve su ürünleri araştırmaları için de önemli bir finansman kaynağıdır (Anonymous, 2008).

AB'nin genişlemesiyle birlikte, asosiye olarak tanımlanan AB'ye aday ülkelerde ÇP aracılığıyla araştırma 
işbirliğine eşit koşullar altında katılım şansı elde etmişlerdir. Bu durum AB'nin ötesinde bir boyut kazanarak daha fazla ülkeye yayılmıştır. Son yıllarda, ÇP, sonuç odaklı araştırma alanlarını destekleyen yeni biçimleri ile, konuya özgü ortaklıklarda kamu ve özel sektör aktörlerini bir araya getiren büyük ortak girişimlerin oluşturulmasına öncülük etmişlerdir. ÇP'n daki ilerlemeler neticesinde, AB Komisyonu ve ulusal hükümetler arasında daha iyi araştırma koordinasyonu sağlanmıştır. Bu kapsamda atılan önemli adımların temeli 1970 ve 1990'lara dayanan ve 2000'li yılların başında Avrupa Araştırma Alanı (European Research Area-ERA) girişiminin başlatılmasıdır (O’Donnell ve Deighton, 2015). AB Anlaşması'nın (Lizbon Anlaşması) 179. maddesine göre, ERA, bilimsel ve teknolojik temellerini güçlendirerek AB'ye yardımcı olabilir ifadesi yer almıştır. Bu anlamda, araştırma ve araştırıcılar için muhtemel veri paylaşımı, sonuçların karşılaştırılması, çok disiplinli çalışmaların yürütülmesi, yeni bilimsel bilgilerin aktarılması ve muhafaza edilmesi ile son teknolojiye sahip ekipmanlara erişim kazanmak amacıyla tek bir Pazar olarak tanımlanmaktadır (Finnegan, 2015). AB'nin ÇP, 30 yıllık bir gelişim sürecinden sonra, Avrupa'da araştırma politikasının temel bir unsuru haline gelmiştir (O’Donnell ve Deighton, 2015).

AB ÇP'n dan biri olan Yedinci Çerçeve Programı (ÇP 7), deniz bilimlerinde sektörler arası araştırmaları teşvik etmektedir (Anonymous, 2014a) ve 2007-2013 yılları arasında yürütülmüştür. Türkiye'nin de aralarında yer aldığı toplam 40 ülkenin katılım sağladığı ÇP 7'nin bütçesi, yaklaşık olarak 50.5 milyar euro tutarında olmuştur. Programın Türkiye ayağı TÜBİTAK tarafından yürütülmüştür. ÇP 7, ERA'yı kurmayı hedefleyen 6. Çerçeve Programı'nın (ÇP 6) başarılarını ilerletme ve Avrupa'da bilgi temelli bir ekonomi ve toplum inşa etme hedefiyle oluşturulmuştur (Servantie, 2015).

ÇP 7, "İşbirliği Özel Programı", "Fikirler Özel Programı", "Marie-Curie Araştırma Programları ve Bursları" ve "Kapasiteler Özel Programı" olmak üzere dört özel programdan oluşmaktadır. AB Ortak Araştırma Merkezi (JRC) ve nükleer araştırmalara destek veren EURATOM programı etkinlikleri de bu dört özel programa dahil edilmiştir (TÜBİTAK, 2012). Balıkçılık yönetimi ile ilgili uzun dönemli araştırma projeleri, AB’nin yeni dönem Araştırma ve Yenilik Çerçeve Programı olan Horizon 2020 kapsamında değerlendirilecektir. Horizon 2020, ÇP 7'nin devamı niteliğinde olup, 2014-2020 dönemi için Avrupa Komisyonu tarafindan yürütülmektedir (Servantie, 2015).

Türkiye, AB ÇP sistemi ile 5. Çerçeve Programı'nda (ÇP 5) proje bazlı işbirlikleri çerçevesinde tanışmıştır (TÜBİTAK, 2012). Helsinki Zirvesi ile 1999 yılında Türkiye'nin adaylık sürecinin başlaması ile birlikte 10 Ocak 2003 tarihinde ÇP 6 ile bu sisteme dahil olmuştur (Pınar ve Uzunoğlu, 2009). Böylece Türkiye hem ÇP 6 hem de ÇP 7'ye asosiye ülke statüsünde katılmıştır. Bu durum, Türkiye'nin Araştırma Alanı'nın ERA ile bütünleşmesi hem de $\mathrm{AB}$ ile bilim ve teknoloji konularında müzakere deneyimi kazanması açısından büyük yarar sağlamıştır (TÜBİTAK, 2012).

$\mathrm{AB}$, müktesebatı için bilimsel ve teknolojik araştırma gerektiren konular ile kendi enstitülerinde yaptığ 1 araştırmalarda, Türkiye'den de araştırmacıların bulunmasına veya Türkiye'deki araştırma kuruluşlarının AB JRC birimleriyle işbirliği içerisinde olmasına, Türkiye Araştırma Alanı'nın ERA ile bütünleşmesi açısından önem vermektedir. $\mathrm{Bu}$ süreç, Türkiye'deki araştırmacıların AB'deki gelişmeleri yakından izlemesine ve oluşum süreçlerine dahil olmalarına katkıda bulunmaktadır. Ayrıca, AB'deki araştırma enstitülerindeki araştırma alt yapısı ve araştırıcı özelliklerinin bilinmesi, olası bu tür araştırma projelerinde ortak bulmak açısından da önem arz etmektedir. Bu bağlamda, bu çalışma ile $\mathrm{AB}$ üye devletlerinden Bulgaristan, İspanya, İtalya, Romanya ve Yunanistan ile aday ülke statüsünde olan Türkiye'nin deniz balıkçılığı alanında faaliyet gösteren kamuya bağlı araştırma enstitülerinde kurumsal kapasite ve araştırıcı özelliklerinin incelenmesi amaçlanmıştır.

\section{Materyal ve Yöntem}

\subsection{Materyal}

Bulgaristan ve Romanya'nın 2007 yılında AB'ye katılımı ile birlikte AB'nin Karadeniz'e olan ilgisi artmıştır. Bulgaristan ve Romanya özellikle kalkan ve çaça balıkları için kota uygulamaktadır. Akdeniz'de ise İspanya, İtalya ve Yunanistan'ın avcılık üzerine ortak çıkarları bulunmaktadır. Bu araştırma konusu için, yukarıda belirtilen hususlar göz önünde bulundurularak, AB'ye üye bu ülkeler ile aday ülke konumunda olan Türkiye seçilmiştir. Bu çalışma, literatüre dayalı olarak hazırlanmıştır. Kapsam dahilindeki ülkelerin deniz balıkçılığı alanında bilimsel faaliyet gösteren kamuya bağlı araştırma enstitülerine ilişkin veriler 2007-2013 yıllarını kapsayacak şekilde FAO, EUROSTAT, TÜİK ve Tarım ve Orman Bakanlığı'nın internet siteleri ve ilgili veri tabanları kullanılarak elde edilmiştir.

Çalışma kapsamında ayrıca AB Parlamentosu yayınları, Avrupa Komisyonu Ortak Araştırma Merkezi ile Balıkçılık Bilimsel, Teknik ve Ekonomik Komitesinin raporları, İktisadi Kalkınma Vakfı (IKKV) değerlendirme notları, OECD (Ekonomik Kalkınma ve İşbirliği Örgütü), TÜBİTAK (Türkiye Bilimsel ve Teknolojik Araştırma Kurumu) ve balıkçılık sektörüne ilişkin raporlar ile konuya ilişkin makaleler incelenerek değerlendirilmiştir.

264 | P a g e

www.iiste.org 


\subsection{Yöntem}

Çalışma yöntemi 2 aşamada gerçekleştirilmiştir. Birinci aşamada, konu ile ilgili olarak literatür taraması yapılmıştır. İkinci aşamada ise incelenen literatürlerin yorumlanması, çeşitli açılardan değerlendirilmesi ve sentezlenmesi yolu ile Türkiye ve seçilen $\mathrm{AB}$ üyesi ülkelerde mevcut durumun ve yaşanan gelişmelerin açıklanması amaçlanmıştır.

\section{Bulgular}

\subsection{Bulgaristan}

3.1.1 Su ürünleri araştırma enstitülerine ilişkin altyapı ve araştırıcı özellikleri

Bulgaristan'da deniz balıkçılığı üzerine kamuya bağlı faaliyet gösteren ve Bulgaristan Bilim Akademisi' ne bağlı Varna'da iki araştırma enstitüsü bulunmaktadır. Bu enstitüler, Varna Su Ürünleri Kaynakları Enstitüsü ile Varna Oşinografi Enstitüsü'dür ve su ürünleri sektörünün organizasyonu ve yönetimi kapsamında Balıkçılık ve Su Ürünleri Ulusal Ajansının (NAFA) faaliyetlerini desteklemekte, Karadeniz'de balık ve diğer su kaynaklarının sürdürülebilir tüketimi için tavsiyeler vermektedir (Popescu, 2011).

Varna Su Ürünleri Kaynakları Enstitüsü'n de faaliyetler hidrobiyoloji ve ihtiyoloji bölümleri tarafından gerçekleştirilmektedir. Enstitü 9 kadın ve 3 erkek olmak üzere toplam 12 araştırıcıdan oluşmaktadır. Araştırıcıların 10'u doktora dereceli olup 2'si lisans mezuniyet derecesine sahiptir (Anonymous, 2016b). Varna Oşinografi Enstitüsü, Ulusal Oşinografi Komisyonu olarak Karadeniz ve dünya okyanuslarıyla ilgili tüm çalışmaların koordinatörü konumundadır ve başarılı bir şekilde UNESCO'nun Hükümetlerarası Oşinografi Komisyonu çerçevesinde araştırma faaliyetlerini ve uluslararası ilişkilerini yürütmektedir. Enstitüde farklı birimlerde çalışan 45 kişi bulunmaktadır (Anonymous, 2016c). Enstitü araştırıcıları 50 'den fazla yenilik sertifikasyonu, 9 patent ve 3'den fazla onay prosedüründe olan paten başvurusuna sahiptir. Enstitü'de 2004 yılında Ulusal Oşinografi Veri Merkezi kurulmuştur. Uluslararası Oşinografi Veri ve Bilgi Değişim Komitesi'nin (IODE) ulusal veri değişim sistemini de içermektedir ve 1990 yllından beri AB, NATO, IOC-UNESCO gibi kurumlarla ortak projeler başlatmıştır. Enstitü, 2007-2013 yılları arasında 24 adet ÇP 7 kapsamında, 6 adet ise farklı fonlardan desteklenen projelerde yer almıştır (Anonymous, 2015a). Enstitüye ait R/V adında bir akademik araştırma gemisi bulunmaktadır. 1979 yılında inşa edilen araştırma gemisi 1984 yılından beri araştırma faaliyetlerini yütümektedir. 1988 yılında bir onarımdan geçerek modern seyir ve bilimsel ekipman ile donatılmıştır (Anonymous, 2016c).

\section{2 Íspanya}

3.2.1 Su ürünleri araştırma enstitülerine ilişkin altyapı ve araştırıcı özellikleri

İspanya Ulusal Araştırma Konseyi (Consejo Superior de Investigaciones Científicas-CSIC) Avrupa'da en büyük üçüncü ve İspanya'da ise araştırma faaliyeti yürüten en büyük kamu kurumudur. Bünyesinde yaklaşık 3.000tanesi doktora derecesine sahip ve eğitimlerine devam eden araştırma personeli olmak üzere 15.000 'den fazla personele sahiptir. İspanya'da araştırma ve geliştirme alanında faaliyet gösteren tüm personelinin \%6'sına CSIC sahip olup, İspanya'daki tüm bilimsel faaliyetlerinde \%20'sini gerçekleştirmektedirler (Anonymous, 2015b).

İspanya Ulusal Araştırma Konseyi bünyesinde doğal kaynaklar alanında çalışan Deniz Bilimleri Enstitüsü, İspanya'nın en büyük deniz araştırma merkezidir. Akdeniz Bölgesi'nde de önemli bir yere sahip olan enstitü çalışmalarını, deniz biyolojisi ve oşinografi, deniz yer bilimi, fiziksel ve teknolojik oşinografi ve yenilenebilir deniz kaynakları gibi farklı alanlarda yürütmekte olup 200'ün üzerinde uzmana sahiptir (Anonymous, 2016d). Enstitüde 2007-2013 yılları arasında 24 adet proje yürütülmüş olup, aynı zamanda 1594 adet bilimsel makale yayınlanmıştır. İlk kez Investigación Pesquera adı altında 1955 yılında yayımlanan ve deniz araştırmaları ile fiziksel ve kimyasal oşinografi, jeoloji, biyoloji ve ekoloji, mühendislik, kıyı yönetimi ve balıkçılık alanlarında orijinal makaleleri içeren Scienta Marina dergisi, Science Citation Indeks'te de listelenen az sayıda dergiden biridir.

İspanya Ulusal Araştırma Konseyi bünyesinde yer alan Deniz Araştırmaları Enstitüsü ise, oşinografi, ekoloji ve deniz kaynakları, biyoteknoloji ve yetiştiricilik ile gıda teknolojisi olmak üzere faaliyetlerini dört alanda sürdürmektedir (EUROSTAT, 2016). Enstitü toplam 118 araştırıcıdan oluşmaktadır, 20112013 yılları arasında 460 bilimsel makale yayımlanmıştır. Enstitü kapsamında 2011-2013 yılları arasında yürütülen proje sayısı ise 5'dir (Anonymous, 2016e).

İspanya Oşinografi Enstitüsü, okyanuslara dair bilimsel veriler, sürdürülebilir balıkçılık kaynakları ve deniz çevresi konularında araştırmalar yapan ve Enstitü Ekonomi ve Rekabet Bakanlığı'na bağlı olarak çalışan kamuya bağlı bir araştırma kuruluşudur. Enstitü, 2001 sayılı Deniz Balıkçılığı Kanunu’na göre, 
devlet kurumunun sektörel balıkçılık politikası araştırmacısı ve danışmanı olarak ifade edilmektedir. Ayrıca deniz ve deniz kaynaklarına ilişkin çoğu uluslararası forum ve organizasyonlarda İspanya'yı bilimsel ve teknik olarak temsil etmektedir. Enstitü yaklaşık 700 personele sahip olup \%80'i araştırmacıdır. Bütçesi 65 milyon euro’yu aşan enstitü geniş bir coğrafyada çalışmalarını yürütmektedir. Balıkçılık, yetiştiricilik ve deniz çevresi olmak üzere üç alanda faaliyet gösteren enstitünün merkezi Madrid'de dir. İspanya kıyıları çevresinde yer alan dokuz oşinografi merkezi bulunmaktadır; bunlar, Galicia (A Coruna ve Vigo), Andalusia (Cadiz ve Malaga), Baleares (Palma de Mallorca), Kanarya Adaları (Santa Cruz de Tenerife), Asturias (Gijon), Murcia (San Pedro del Pınatar) ve Santander' dir. Balıkçılık bölümü tarafından 18 proje, yetiştiricilik bölümü tarafından 4, deniz ve çevre koruma bölümü tarafından ise 20 adet, toplamda ise 42 adet proje enstitü aracılığı ile gerçekleşmiştir. İspanya Oşinografi Enstitüsü 1982 yılından 2007 yılına kadar teknik rapor yayınlamıştır. 2007 yılında bu serinin son cildi 187 ile düzenleme durdurulmuştur. Makaleler İngilizce ya da İspanyolca olarak yayımlanmıştır, 1916-2007 yılları arasında dergi çıkaran enstitü bu yayın serisini ise 2007 yılında 23. cilt ile sonlandırmıştır. Biyoloji, ekoloji, fizik, kimya, balıkçılık, su ürünleri yetiştiriciliği ve kirlilik gibi farklı alanlar ile deniz bilimleri ve oşinografi konusunda bir bilim dergisidir. Araştırma makaleleri, teknik derlemeler, sempozyum ve konferansa ilişkin bilgiler içeren İspanyolca ve İngilizce yayın yapmıştır. Enstitü, biri Galicia'da, ikisi Cantabria'da, biri Kanarya Adaları ve Murcia'da olmak üzere 5 yerde deneysel kültür balıkçılığı; 12 gelgit ölçeği istasyonları ve uydu görüntüleri için alıcı istasyonlarına sahiptir. Enstitü'nün altyapı olanakları içerisinde yetiştiricilik tesislerinin yanı sıra geniş bir filosu da bulunmaktadır. Enstitü 14 ve 65 metre uzunluk aralığında beş tane araştırma balıkçı gemisinin yanı sıra diğer küçük balıkçı teknelerinden oluşan bir filoya sahiptir. Araştırma gemileri en modern elektronik deniz sistemleri ile donatılmıştır. Araştırma gemileri hem suda hem de sedimentte örnek toplamakta, deniz suyu değişkenlerinin fiziksel ve kimyasal özelliklerinin belirlenmesi, deniz florası ve faunası üzerine çalışmalar yürütmektedir (Anonymous, 2016f).

Deniz Araştırma Merkezi, Galicia Özerk Bölgesinin coğrafi yetki alanında yenilenebilir deniz kaynaklarının etkin yönetimini elde etmek amacıyla belli bir hedef doğrultusunda uygulamalı araştırmalar yürütmektedir. Merkez, Deniz Bakanlığı'na bağlı olup Arousa Vilnaova'da (Pontevedra) Coron Deniz Araştırmaları Merkezi ve Ribadeo (Lugo)'da bir kültür balıkçılığı tesisine sahiptir (Anonymous, 2016g) ve kıyı oşinografisi, deniz kaynakları, yetiştiricilik ve patoloji alanlarında faaliyetlerini sürdürmektedir. Coron Deniz Araştırmaları Merkezi' nde 29, Ribadeo (Lugo)'da ki tesiste ise 8 adet araştırıcı görev yapmaktadır (Anonymous, 2016g).

\subsection{Italya}

3.3.1 Su ürünleri araștırma enstitülerine ilişkin altyapı ve araştırıcı özellikleri

Balıkçılık ve yetiştiriciliğe dair temel araştırmaların çoğunluğu çeşitli üniversite enstitüleri tarafından yapılmaktadır. Ulusal Araştırma Konseyi (National Research Council-CNR-Consiglio Nazionale delle Ricerche), Denizde Uygulanan Bilimsel ve Teknik Araştırma Merkez Enstitüsü (ICRAM-Istituto Centrale per la Ricerca scientifica e tecnologica Applicata al Mare) ve Yeni Teknolojiler, Enerji ve Çevre Ajansı (ENEA-Ente per le Nuove tecnologie, l'Energia e l'Ambiente) aracılığıyla uygulamalı olarak araştırma ve veri toplama çalışmaları yürütülmektedir. Temel balıkçılık araştırma merkezleri olan Ancona, Adriatik, Mazara del Vallo ve Sicilya Kanal, CNR merkezleridir. Ekonomi ve piyasa bilgisi Ulusal İstatistik Birimi (Istituto Nazionale di Statistica-ISTAT), ICRAM ve Su Ürünleri Ekonomisi Araştırma Enstitüsü (Istituto Ricerche Economiche per la Pesca e l'Acquacoltura-IREPA) tarafından toplanıp, işlendikten sonra kullanılmaktadır (Iborra Martin, 2008).

Balıkçılık ve tarım üzerine araştırma projeleri için devlet fonlarının ana kaynağı Tarım Bakanlığı (Ministero por le Politiche Agricole) ve CNR'dır (Iborra Martin, 2008) ve 2002 yılından itibaren AB Tüzükleri'nin temel alındığı OBP ile ilgili balıkçılık verilerini toplama amaçlı bir ulusal program geliştirilmiştir (FAO, 2016).

Deniz Biyolojisi İtalyan Topluluğu (Società Italiana di Biologia Marina-SIBM) deniz biyolojisi üzerine çalışan araştırıcılar için ilişki kuran bir çerçeve niteliği taşımaktadır. Söz konusu topluluk, toplantı ve seminer organize etmekte ve çeşitli ulusal ve uluslararası araştırma programlarını yönetmektedir (Iborra Martin, 2008).

Deniz Bilimleri Enstitüsü Akdeniz'de, okyanusta ve kutup bölgesinde araştırmalar yürütmektedir. Enstitü, 2007-2013 yılları arasında tamamlanmış 2 ulusal, 6 uluslararası ve 21 adet devam eden uluslararası projeye sahiptir, ayrıca deniz araştırmalarını yürütmek amacıyla 6 araştırma gemisi/motoru da bulunmaktadır (Anonymous, 2016h).

Kıyı Deniz Çevresi Enstitüsü (IAMC), 2002'de önceden var olan dört enstitünün birleşmesi ile kurulmuştur. IAMC, genel merkezinin yer aldığı Napoli'nin güneyinde jeo-deniz araştırma enstitüsü, 
Deniz Kaynakları ve Çevre Enstitüsü’nün Mazara del Vallo uygulama birimi, önceki Thalassographic Deneysel Enstitüsünün Messina uygulama birimi ve önceki Thalossographic Enstitüsü’nün Taranto'daki uygulama biriminin birleşmesi ile oluşturulmuş bir enstitüdür. Enstitü, ayrıca önceden Genova'daki Sibernetik ve Jeofizik Enstitüsü'nün Duyusal Sistemler ve Deniz Çevresi Bölümünden elde edilen Oristano'daki uygulama birimi ile Capo Granitola'daki birimini 2007 yılında kurmuştur (Anonymous, 20161).

Uluslararası Araştırma Konseyi IAMC, altı bölüm ve bir deniz biyolojisi laboratuvarından oluşmaktadır. Deniz bilimleri alanında faaliyet gösteren enstitü yenilenebilir kaynaklar ve deniz teknolojisi üzerine özellikle biyoloji, kimya, fizik ve jeoloji alanlarında çalışmalar yürütmektedir (Anonymous, 20161).

\subsection{Romanya}

3.4.1 Su ürünleri araştırma enstitülerine ilişkin altyapı ve araştırıcı özellikleri

Romanya'da deniz balıkçılığa alanında faaliyet gösteren kamuya ait araştırma enstitüsü "Grigore Antipa" Köstence Ulusal Deniz Araştırma ve Geliştirme Enstitüsü (NIMRD)'dür. Enstitü, oşinografi, deniz ve kıyı mühendisliği, deniz ekolojisi ve çevre koruma ile Karadeniz'deki ve diğer deniz alanlarındaki canlı kaynakların yönetimi açısından uygulamalı ve araştırma-geliştirmeye yönelik faaliyetlerini yürütmektedir. Münhasır ekonomik bölgenin ulusal ve uluslararası gerekliliklerinin yanı sıra alanında uluslararası sözleşmelerle Romanya'nın üyeliği ile getirilen yükümlülükleri karşılamaktır. Deniz bilimleri alanındaki yönetmelikleri, Çevre ve İklim Değişiklikleri Bakanlığına teklif etme hakkına sahiptir. NIMRD fiziksel, kimyasal ve biyolojik izleme ile kıyı erozyonu gözleminin teknik uygulayıcısı konumundadır (Anonymous, 2016j). Enstitü, deniz ve kıyı çevresini bütünleşik izleme, Romanya deniz sularındaki yunusların koruma ve muhafazası ve deniz radyoaktitvitesi ile radyoekolojisi alanlarında ulusal ve uluslararası programlar yürütmektedir (Anonymous, 2016b). Enstitü kapsamında toplam 31 araştırıcının 25'i doktora ve 6's1 ise lisans düzeyinde eğitime sahiptir. En fazla doktora eğitimine sahip meslek grubu su ürünleri mühendisleri olmuştur. Enstitü kapsamında "Cercetări Marine-Recherches Marines” adlı yayın 1971 yılından beri düzenli olarak çıkarılmaktadır, 2007-2013 yılları arasında beş sempozyum düzenlenmiştir. Enstitü tarafından tamamlanan toplam 33 projenin 16'sını uluslararası proje, 15'ini ulusal proje ve 2'sini yapısal fon projeleri oluşturmaktadır (Anonymous, 2016j).

\subsection{Yunanistan}

3.5.1 Su ürünleri araştırma enstitülerine ilişkin altyapı ve araştırıcı özellikleri

Balıkçılık Araştırma Enstitüsü, balıkçılık sektöründe araştırmalar yürüten ve teknolojik gelişmenin teşvik edilmesinden sorumlu olan Ulusal Tarımsal Araştırma Kuruluşu (NAGREF)'in uzmanlaşmış beş enstitüsünden biridir. Enstitü, Kavala şehrinden $17 \mathrm{~km}$ uzaklıkta yer almaktadır (Anonymous, 2015c) ve 1993 yılında NAGREF’e bağlı olarak kurulmuştur (Fuchs, 2000). Agri-med alanındaki yıllık bütçesi 2008 yılında 882.000 euro'dur (Anonymous, 2015d). Enstitü, içsular ve lagünler, deniz balıkçılığı, iç su balıkları yetiştiriciliği ve deniz balıkları yetiştiriciliği olmak üzere dört bölümden oluşmaktadır. Enstitü bünyesinde deniz balıkçılığı alanı ile ilgili olarak toplam 24 kişi çalışmakta olup araştırıcılardan 7'si kadın 17'si ise erkektir, 24 araştırıcının 5'i doktora, 5'i yüksek lisans, 6'sı lisans ve 1'i önlisans mezunudur. Araştırıcılar ağırlıklı olarak, biyoloji ve ihtiyoloji bölümlerinden mezun olup, balıkçılık ürünlerinin geliştirilmesi ve kullanımı alt bölümünde gıda ve kimya bölümlerinden araştırıcılar da yer almaktadır. Enstitünün 2007-2013 yılları arasında yürütmüş olduğu 5 ulusal ve 1 tane de uluslararası proje olmak üzere toplam 6 adet projesi bulunmaktadır (Anonymous, 2015c).

Yunan Deniz Araştırmaları Enstitüsü, Ulusal Deniz Araştırmaları Enstitüsü (National Center for Marine Research-NCMR) ile Girit Deniz Biyolojisi Enstitüsü’nü (Institute of Marine Biology of Crete-IMBC) birleştiren 164/2003 sayılı başkanlık kararnamesi ile 2003 yılında kurulmuştur. Yunan Deniz Araştırmaları Enstitüsü üretilen sonuçların deneysel gelişimini, dağıtımını ve uygulanmasını bilimsel ve teknolojik araştırmalar bakımından yürütmeyi amaçlamaktadır (Anonymous, 2015e). Merkez, Oşinografi Enstitüsü, Deniz Biyolojik Kaynakları ve İçsular Enstitüsü, Deniz Biyoloji ve Genetiği ile Yetiştiricilik Enstitüsü olmak üzere üç enstitüden oluşmaktadır.

Yunanistan'da oşinografi çalışmaları 1930'lu yılların sonlarına dayanmaktadır. Ancak 1980'li yılların ortasına kadar çoğunlukla kıyı çevresindeki faaliyetleri kapsamaktadır. Oşinografi Enstitüsü, Ulusal Deniz Araştırmaları Merkezi'nin (National Centre for Marine Reseacrh-NCMR) üç biriminden biri olarak 1985 yılında kurulmuştur ve 1990'lı yıllara kadar ulusal projelerle birlikte Avrupa Komisyonu tarafından multidisipliner projelerin katılımının artmasının bir sonucu olarak hem faaliyetleri hem de personeli açısından hızlı bir şekilde büyüme gerçekleştirmiştir. Enstitü, Avrupa deniz araştırmalarında ve Doğu Akdeniz bölgesinde ki çalışmalarda faaliyet göstermektedir (Anonymous, 2015e). Enstitüde fizik, kimya, biyoloji ve çevre gibi uzmanlık alanlarına sahip toplam 59 kişi çalışmaktadır. 
Deniz Biyolojik Kaynakları ve İçsular Enstitüsü, AB politikası kapsamında, Yunanistan'da yer alan nehirlerin su kalitesi ve miktarı açısından örneklenmesine ilişkin çalışmalar yürüterek Ulusal İzleme Ağı'na katkı sağlamaktadır. Ensititü, balıkçılık verilerinin toplanması ve sürdürülebilir balıkçılık hedeflerini elde etmeye yardımcı olmak amacıyla balık populasyonlarına ilişkin biyolojik parametreler ve coğrafik sınır bilgisi ile balıkçılık yönetimi hakkında gerekli bilgiler sağlamaktadır. Enstitü, Yunanistan deniz çevresi için ayrıntılı bir değerlendirme yapabilmek amacıyla araştırma kuruluşları ile birlikte çalışır. Bu kapsamda Deniz Strateji Çerçeve Direktifinin uygulanmasına katkı sağlamaktadır (Anonymous, 2015f). Enstitünün misyonu sucul biyolojik kaynakların, habitatların ve ekosistemlerin korunması ve yönetimini desteklemek, çevre koruma ve yönetimi hakkında ulusal, Akdeniz, AB ve diğer uluslararası kuruluşlara bilimsel rehberlik ve hizmet sağlamak ve sucul biyolojik kaynakların, habitatların ve ekosistemlerin korunmasına ilişkin konular hakkında geniş çapta kamuyu duyarlı hale getirmektir (Anonymous, 2015f). Enstitünün Deniz Biyolojik Kaynakları bölümü bünyesinde 13'ü kadın, 12'si erkek olmak üzere toplam 25 araştırıcı bulunmaktadır, 19 araştırıcı doktor ünvanına sahip olup 18 araştırıcı biyoloji bölümünden mezundur.

Deniz Biyolojisi, Genetiği ile Yetiştiricilik Enstitüsü, 2012 yılında Deniz Biyolojisi ve Genetiği Enstitüsü ile Yetiştiricilik Enstitüsü'nün birleştirilmesi ile oluşturulmuştur. Bu kapsamda populasyon genetiği, filocoğrafya, sistematik, deniz, tatlısu türlerinin filogenetik ve evrimsel tarihi, genom, gen haritalama, çeşitli yaşam evreleri ve çevresine ilişkin gen ekspresyonu ve mikrobiyal çeşitliliğe ilişkin çalışmalar genetik ve moleküler biyoteknoloji bölümü tarafından yürütülmektedir. Enstitünün Deniz Biyolojisi ve Genetiği Bölümü'nde toplam 20 araştırıcı olup kadın ve erkek araştırıcıların sayısı eşit dağılım göstermektedir. Enstitüde 10 araştırıcı doktora, 4'ü yüksek lisans ve 6'sı ise lisans mezunudur. En fazla biyoloji alanından mezun araştırıcı çalışmakta olup sayıları 10'dur. Bu sayıyı, 3 kimya mezunu araştırıcı ve 2 tane de su ürünleri bölümü mezunu araştırıcı takip etmektedir. Yetiştiricilik alanındaki projelerin dışında, 2007-2013 yılları arasında 34 ulusal proje yürütülmüştür. Aynı şekilde, aynı yıllar arasında yürütülen uluslararası projelerin sayısı 29'dur (Anonymous, 2015e).

\subsection{Türkiye}

3.6.1 Su ürünleri araştırma enstitülerine ilişkin altyapı ve araştırıcı özellikleri

1987 yılında “Trabzon Su Ürünleri Araştırma Enstitüsü” olarak kurulan Su Ürünleri Merkez Araştırma Enstitüsü Müdürlüğü, 1988 yılından itibaren uygulamalı araştırma faaliyetlerine başlamıştır. Bölgesel bazda faaliyet gösteren enstitü, 1998 yılındaki Bakanlık Makam oluru ile birlikte Merkez Enstitüsü statüsü kazanarak faaliyetlerini ülkesel düzeye çıkarmış ve bu tarih itibariyle "Su Ürünleri Merkez Araştırma Enstitüsü-Trabzon" olarak ismi değişmiştir. Karadeniz, Marmara ve Kuzey Doğu Anadolu sorumluluk alanına giren bölgelerdir. Enstitü özellikle Karadeniz olmak üzere Türkiye'de deniz ve içsular alanında su ürünleri üzerine araştırmalar yapmakta ve bu araştırma sonuçlarını uygulamaya aktarmakla ilgili çalışmalar yürütmektedir (Anonim, 2016a). Enstitü, yedi bölümde faaliyetlerini sürdürmektedir. Yetiştiricilik Bölümü, liman işletmesi, kapalı devre tatlı su ünitesi ve deniz balıkları kuluçkaevi ve inşaat halinde olan bir yeni üniteden oluşmaktadır. Deniz ürünleri yetiştiriciliği, içsu ürünleri yetiştiriciliği, yetiştiricilik teknolojisi, balık beslemesi adaptasyon, hizmet, danışmanlık gibi diğer faaliyetler kapsamında Karadeniz alabalığı, Karadeniz kalkanı, mersin ve kırlangıç balığı üzerine çalışmalar yürütmektedir. Balıkçılık Yönetimi Bölümü Karadeniz ve Marmara Denizi ile içsularda ekonomik öneme sahip türlerin stok tahminleri ve biyo-ekolojik özelliklerinin incelenmesi, balık markalama ile göç yollarının tespit edilmesi, av araçlarının zararlı etkilerinin azaltılması ve besin dinamiğine yönelik çalışmalar yürütmektedir. İşleme ve Değerlendirme Bölümü, 2002 yılında JICA desteği ile alt yapısı tamamlanarak kurulmuştur. Su Ürünleri Sağlığı Bölümü hastalıkların kontrol altına alınması, hastalıkların epidiyomolojisi ve mevcut alandaki su ürünleri sağlığı ile ilgili sorunların çözümüne yönelik olmak üzere araştırma ve çalışmalar yürütmektedir. Çevre ve Kaynak Yönetimi Bölümü oşinografi, limnoloji, çevre ve kaynak tespiti üzerine çeşitli araştırma ve çalışmalar yürütmektedir. Merkez Enstitü statüsünün 1998 yılında kazanılması ile kurulan Islah ve Genetik Bölümünde ise su ürünleri üzerine biyoteknolojik uygulamalar, moleküler uygulamalar, ıslah ve melezleme çalışmaları yürütülmektedir. Tarım Ekonomisi Bölümü sosyo-ekonomik çalışmalar, tüketici davranışları, kooperatifler, veri tabanı oluşturma, politika ve ekonomiye dayalı çalışmalar yürütmektedir. Enstitü kapsamında toplam araştırıcı sayısı 49 olup, araştırıcıların 12' sinin kadın ve 37'sinin erkek olduğu gözlemlenmiştir, 49 araştırıcının 22'si yüksek lisans $15^{\prime} \mathrm{i}$ ise doktora derecesine sahiptir. Meslek grupları açısından değerlendirildiğinde, araştırmacıların 13'ünün Balıkçılık Teknolojisi Mühendisi ve 11'inin ise Su Ürünleri Mühendisi olduğu saptanmıştır. Bu sayıyı 4'er kişi ile Ziraat Mühendisliği ve biyoloji mezunu araştırıcılar takip etmektedir. Enstitü kapsamında Turkish Journal of Fisheries and Aquatic Sciences, Genetics of Aquatic Organisms (GenAqua) ve Yunus Araştırma Bülteni olmak üzere üç enstitü yayını bulunmaktadır. Enstitünün 2007- 
2013 yılları arasında 358 ulusal ve 115 uluslararası yayına ve toplam 42 projeye sahip olduğu görülmüştür. Enstitünün Sürat Araştırma 1 ve Sürat Araştırma 3 olmak üzere iki araștırma gemisi bulunmaktadır. Akdeniz Su Ürünleri Araştırma, Üretme ve Eğitim Enstitüsü Müdürlügüü, Ege ve Akdeniz Bölgeleri’nde içsularda ve denizlerde araştırma faaliyetlerini yürütmek amacıyla Antalya Kepez Su Ürünleri Üretme İstasyonu, Beymelek Su Ürünleri Üretim ve Geliştirme Merkezi ile Bodrum Su Ürünleri Araştırma Enstitüsü olmak üzere üç enstitünün birleşmesi ile kurulmuştur. Enstitü çalışmalarına Merkez Beymelek ve Kepez Birimi olarak devam etmektedir. Enstitü balıkçılık yönetimi, su ürünleri sağlığı, yetiştiricilik ve ekolojik içerikli araştırmalar yürütmektedir. Enstitü kapsamında toplam araştırıcı sayısı 41 olup, araştırıcıların 8'inin kadın ve 33'ünün erkek olduğu gözlemlenmiştir ve 41 araştırıcının 12'si yüksek lisans 3'ü ise doktora derecesine sahiptir. Meslek grupları açısından değerlendirildiğinde, araştırmacıların 11 'inin Su Ürünleri Mühendislerinden oluştuğu ve bu oranın diğer meslek grupları ile kıyaslandığında yüksek olduğu saptanmıştır. Enstitü 2007-2013 yılları arasında toplam 22 proje çalışması yürütmüştür. Enstitüde 2007-2013 yılları arasında ulusal 100 ve uluslararası 47 olmak üzere toplam 147 makale yayımlanmıştır. Enstitü Müdürlüğü tarafından, Su Ürünleri ile ilgili bilimsel özgün çalışmaları içeren "Journal of Academic Documents for Fisheries and Aquaculture" adlı dergi Nisan 2014 tarihinden itibaren yayın hayatına geçmiştir ve 2007-2013 yılları arasında ulusal ve uluslararası 11 adet sempozyum düzenlenmiştir. Özellikle açık denizlerde sivil denetleme hizmetlerinin yerine getirilmesi ve araştırma hizmetlerinin yürütülmesi amacıyla da ARAMA-1 gemisi, Araştırma ve Kontrol Gemisi olarak uluslararası sularda faaliyet göstermek üzere 2014 yılında hizmete girmiştir.

\section{Sonuç ve Değerlendirme}

AB'ye üye ülkelerdeki balıkçılık yönetimi için temel koşullar OBP tarafından belirlenmektedir. Bu politika ilkeleri çerçevesinde balık stoklarının ve çevresel korumanın kuralları belirlenmektedir. $\mathrm{Bu}$ kuralları belirlemede bilimsel tavsiyenin önemi büyüktür. Araştırma enstitülerinin yürütmüş olduğu bilimsel faaliyetler bilimsel tavsiye verme hususundaki rolünü de ön plana çıkarmaktadır. Bu çalışma kapsamında, incelenen araştırma enstitülerinin OBP mevzuatının yanı sıra, Su Stratejisi Çerçeve Direktifi ve Deniz Stratejisi Çereçeve Direktifi'ne ilişkin mevzuata yönelik de uygulamalar gerçekleştirdikleri tespit edilmiştir. Bu durum aslında su ürünleri sektörünün sadece OBP ile bağlantılı olmayıp aynı zamanda AB'nin Çevre Politikaları ile de bir bütün oluşturduğu şeklinde yorumlanabilir. Türkiye'nin, incelenen beş $\mathrm{AB}$ üye ülkesinin araştırma faaliyetleri açısından konumu değerlendirildiğinde araştırma alt yapı olanaklarının $\mathrm{AB}$ ülkelerine eşdeğer olduğu ve ÇP 7 altında benzer araştırma ve proje faaliyetlerini yürüttükleri ve ortak çalışmalar yaptıkları tespit edilmiştir. İncelenen AB ülkelerinde merkezi bir araştırma enstitüsü bünyesinde bölgelere göre dağılım gösteren bir yapı gözlemlenmektedir. Aynı durum Türkiye için Akdeniz Su Ürünleri Araştırma Enstitüsü’n de de gözlemlenmiştir. Ülkelere göre enstitülerde çalışan araştırıcıların cinsiyet dağılımı ile ilgili veriler Bulgaristan, Yunanistan ve Türkiye'den elde edilmiştir. Buna göre, Yunanistan ve Türkiye'de erkek araştırmacıların daha yoğun olduğu buna karşın Bulgaristan'da kadın araştırıcı sayısının yüksek olduğu gözlemlenmiştir. Enstitülerdeki araştırıcıların eğitim düzeyleri açısından değerlendirme yapıldığında ise araştırıcı sayısına oranla Bulgaristan ve Yunanistan'ın doktora eğitim düzeyinin yüksek olduğu özellikle de Yunanistan'ın öne çıktığı görülmektedir. Türkiye'de de araştırma enstitülerinde doktoralı araştırmacılar olmasına rağmen daha çok araştırıcıların yüksek lisans derecesinde dağılım gösterdiği gözlemlenmiştir. Tüm enstitüler kendi bünyelerinde makaleler yayınlamaktadır. Türkiye, İspanya, Romanya'daki araştırma enstitüleri indeksli olarak kendi yayınlarını bünyelerinde bulundurmaktadır. Enstitülerde çalışan araştırıcıların meslek gruplarına göre dağılımına baktığımızda Romanya ve Türkiye'deki araştırıcıların büyük çoğunluğunu Su Ürünleri Mühendisi ya da Balıkçılık Teknolojisi Mühendislerinin oluşturduğu, ikinci sırada ise biyoloji bölümü mezunlarının yer aldığı gözlemlenmiştir. Yunanistan'daki araştırıcıların ise çoğunlukla biyolog meslek grubundan oluştuğu saptanmıştır. İncelenen ülkelerin çoğu okyanus ve denizlerde araştırma faaliyetlerini yürütmek amacıyla araştırma gemilerini bünyelerinde bulundurmaktadır. Özellikle İspanya ve İtalya'da ki araştırma gemi sayıları altıya kadar yükselmiştir.

Sonuç olarak, Türkiye'nin, 2007-2013 döneminde yürütülen ÇP 7' de olduğu gibi, AB bilim programları ve proje ortaklıkları bakımından diğer AB ülkeleri ile eşdeğer bir konumda yer aldığı ve önemli bir paydaş olabileceği bu çalışma ile gösterilmiştir.

\section{Kaynaklar}

Anonim. (2012). 2013 Sonrası Avrupa Birliği Ortak Balıkçılık Politikası. [Online Available]: http://www.abgs.gov.tr (May 06, 2014).

Anonim. (2016a). [Online Available]: arastirma.tarim.gov.tr/sumae (December 15, 2016). 
Anonim. (2016b). [Online Available]: arastirma.tarim.gov.tr/akdenizsuurunleri (December 15, 2016).

Anonymous. (2008). The Common Fisheries Policy-Fact sheets. [Online Available]: http://ec.europa.eu (May 19, 2014).

Anonymous

(2014a).

[Online

Available]: http://ec.europa.eu/research/bioeconomy/fish/policy/index_en.htm (May 22, 2014).

Anonymous. (2014b). [Online Available]: http://ec.europa.eu/fisheries/cfp/index_en.htm (May 21, 2014).

Anonymous. (2015a). Operational Program Fisheries Sector Development 2007 - 2013 Strategy and description of priority axis and measures. Sofia.

Anonymous. (2015b). [Online Available]: http://www.csic.es/presentacion (February 25, 2015).

Anonymous. (2015c). [Online Available]: http://www.arimnet.net/GR_facsheet_arimnet_countries_research_systems_final.pdf (February $16,2015)$.

Anonymous. (2015d). [Online Available]: http://www.fishri.gr (February 16, 2015).

Anonymous. (2015e). [Online Available]: http://www.hcmr.gr/en/ (February 17, 2015).

Anonymous. (2015f). [Online Available]: http://imbriw.hcmr.gr/en/ (February 18, 2015).

Anonymous. (2016a). [Online Available]: http://ec.europa.eu/research (November 15, 2016).

Anonymous. (2016b). [Online Available]: https://ec.europa.eu/fisheries/home_en (November 30, 2016).

Anonymous. (2016c). [Online Available]: http://www.ifrvarna.com (February 10, 2016).

Anonymous. (2016d). [Online Available]: http://www.io-bas.bg (October 19, 2016).

Anonymous. (2016e). [Online Available]: http://www.ieo.es (November 11, 2016).

Anonymous. (2016f). [Online Available]: http://www.iim.csic.es (November 12, 2016).

Anonymous. (2016g). [Online Available]: http://mar.xunta.gal (November 12, 2016).

Anonymous. (2016h). [Online Available]: http://www.ismar.cnr.it/ (November 16, 2016).

Anonymous. (20161). [Online Available]: http://www.iamc.cnr.it (November 17, 2016).

Anonymous. (2016j). [Online Available]: http://www.rmri.ro (November 8, 2016).

DPT (Devlet Planlama Teşkilatı). 2003. Su Ürünlerinde Eğitim, Araştırma ve Geliştirme. Su Ürünleri Özel İhtisas Komisyonu Raporu. SUMAE YUNUS Araştırma Bülteni, 3, 2.

Eman Gökseven, Ş. B., Meriç Turgut, İ., Ataseven, Y. (2018). Türkiye’de ve Avrupa Birliği üyesi bazı ülkelerde balıkçılık sektörünün değerlendirilmesi. Ziraat, Orman ve Su Ürünleri Alanında Yenilikçi Yaklaşımlar. Ankara: Gece Publishing, (Bölüm 12).

EUROSTAT. (2016). [Online Available]: http://ec.europa.eu/eurostat (November 15, 2016).

FAO (Food and Agriculture Organization). (2016). [Online Available]: 
http://www.fao.org/fishery/facp/ITA (November 17, 2016).

Finnegan, G. (2015). Europe's Framework Programmes: A Key Element of Research Policy in Europe. Horizon Magazine. Special Issue March, 25.

Fuchs, J. (2000). Fisheries research organizations and research programmes in the European Union, Iceland, Israel and Norway. European Commission Directorate-General for Fisheries. Italy.

Iborra Martin, J. (2008). Fisheries in Italy. Policy Department: Structural and Cohesion Policies. Directorate-General for Internal Policies of the Union. Brussels.

Kilit, G. (2012). Avrupa Birliği Ortak Balıkçılık Politikası'nın Reformu. İKV Değerlendirme Notu. İktisadi Kalkınma Vakfi, 62.

O’Donnell, P., Deighton, B. (2015). Europe's Framework Programmes: A Key Element of Research Policy in Europe. Horizon Magazine. Special Issue March, 3-4.

Pınar, Ö., Uzunoğlu, H. (2009). Avrupa Birliği’nin Ar-Ge Politikaları ve Türkiye’nin Uyumu. İzmir Ticaret Odası. AR-GE Bülten.

Popescu, I. (2011). Fisheries in Bulgaria. Policy Department B: Structural and Cohesion Policies. Directorate-General for Internal Policies. Brussels.

Servantie, D. (2015). Türkiye ve AB arasında bilim ve araştırma alanında işbirliği. İKV Değerlendirme Notu. İktisadi Kalkınma Vakfı, 166.

TÜBİTAK (Türkiye Bilimsel ve Teknolojik Araştırma Kurumu). (2011). AB 7. Çerçeve Programı'nda Türkiye (2007-2011). [Online Available]: http://www.fp7.org.tr (May 30, 2014).

TÜBİTAK (Türkiye Bilimsel ve Teknolojik Araştırma Kurumu). (2012). AB 7. Çerçeve Programı Ara Değerlendirme Raporu-Ek 1 (1 Ocak 2007-30 Haziran 2012). 